\title{
Assessing the Exposure Risk of Regional Populations to Smoke from Fires
}

\author{
C. P. Meyer $^{\text {a,b }}$, M. Cope ${ }^{\text {a,b }}$ and S. Lee ${ }^{\text {a,b }}$ \\ ${ }^{a}$ CSIRO Division of Marine and Atmospheric Research, Private Bag No. 1 Aspendale 3195 Victoria \\ ${ }^{b}$ Bushfire CRC, Albert St, East Melbourne, Victoria \\ Email:mick.meyer@,csiro.au
}

\begin{abstract}
The potential health impacts from smoke are well known. Protracted exposure of rural and urban populations, particularly the more susceptible groups including the elderly, people with impaired cardiovascular function and allergies, extends the risk from bushfires to the entire population and, in some cases, due to the number of people exposed, may constitute the greatest risk to health. The cost of these impacts can be substantial. Consequently smoke management is now a major issue for fire agencies. The exposure risks vary widely with the class and location of the fire events, and range from extensive fumigation of SE Australian populations from fires that persist for weeks to localised impacts from small fires. The fire decision tools project of the Bushfire Cooperative Research Centre has been developing techniques for assessing the risks and impacts through a series of case studies. The key issue to emerge is not the total emission of smoke, but the extent to which the emissions mix back into the surface layer, and the persistence of the smoke in the air shed.

This study analyses the smoke dispersion and regional health impact on population of three fire events of the last decade: the 2006 alpine fire, the Kilmore East fire of Black Saturday ( $8^{\text {th }}$ February 2009), and a high intensity prescribed burning event in the Huon Valley, Tasmania in April 2010. Relative health impact was assessed by combining the mean daily surface PM2.5 concentration from smoke during the duration of each event, with population density and the mortality risk factor of $1 \%$ increase in mortality per $10 \mu \mathrm{g} \mathrm{m}^{-3}$ increase in PM2.5 concentration. The greatest health impact was from the 2006 alpine fire, which burned $1.1 \mathrm{Mha}$ over a period of 60 days. Smoke from the fire significantly impacted all of Victoria, including the Melbourne air shed, and producing a risk equivalent to an increase in mortality of 84 . This was largely due to the long duration of the event which led to widespread smoke dispersion that reflected seasonal climatology. In contrast, the impacts from the Kilmore East fire and the Huon Valley prescribed burning events were minor, primarily because smoke did not impact regions of high population density and the events were of short duration and therefore determined by the weather of the day. All events emitted large amounts carbon to the atmosphere; however the size of the emission was not a reliable indicator of risk to health.
\end{abstract}

Prescribed burning is extensive, it averages approximately $70 \%$ of the annual fire area in Victoria, and is confined to a relatively short season. While individual fires are small and short lived, collectively they are a large distributed source and may function similarly to a single large protracted wildfire event. The policy to increase the current rate by $250 \%$ to 400 kha per year therefore will pose significant challenges for regional managers if PM2.5 impacts on population health are to be avoided.

Keywords: Biomass burning, wildfires, fuel reduction burning, transport modelling, smoke hazard 
Meyer et al., Smoke impacts from prescribed burning in Victoria; developing a risk climatology.

\section{INTRODUCTION}

The Mediterranean climate of southern Australia coupled with the patterns of settlement has developed a regime of regular summer wildfires. While the objective of the land management by prescribed burning is to minimize the damage to ecosystems and property and to prevent injury to people by containing, and where possible by suppressing these wildfires, occasionally conditions combine to produce fires that are extensive and sometimes catastrophic. In the last century there have been several of these events; several within the last decade across southern Australia. To reduce the risk of wildfires and also for silvicultural and biodiversity management, the state fire agencies conduct regular programs of prescribed burning. In Victoria, for example, until the events of Black Saturday 2009, approximately $1.5 \%$ of the total area was burned under prescription, but the events of Black Saturday, 2009, led to a recommendation that this be increased to $5 \%$ annually (Teague et al., 2010); this has now been accepted by the State Government as policy. The result is that either by prescription or unplanned, fires are a major feature of these landscapes.

All these fires produce large quantities of smoke, and smoke impacts health. Occupational health studies of fire-fighters (e.g. Reisen and Brown, 2009) have concluded that particulate matter (PM), particularly PM2.5, is the constituent of most concern, and there have been many studies that have found a correlation between exposure to elevated concentrations of PM and mortality. These are reviewed by Pope and Dockery (2006) who concluded that a there is a $1 \%$ increase in mortality for every $10 \mu \mathrm{g} \mathrm{m}^{-3}$ increase in the mean daily concentration of PM10, however far higher impacts are also commonly reported: Lepeule et al. (2012) report a $14 \%$ increase in mortality from all causes per $10 \mu \mathrm{g} \mathrm{m}^{-3}$ increase in PM2.5. The rates were higher by disease class: $26 \%$ for cardiovascular mortality and $36 \%$ for lung cancer mortality. Miller et al. (2007) reported a $76 \%$ increase in cardiovascular mortality in post-menopausal women. Many of studies are also now showing significant impacts on morbidity (e.g., Johnston et al., 2007).

The nature of the fires is diverse; the range from small area prescribed burns, to larger wildfires that are confined and managed, to extreme events, fortunately uncommon, that destroy huge areas of forest; sometimes quickly and catastrophically, and sometimes slowly, persisting for weeks or months. Transport and impact of smoke from wildfires is usually a secondary focus of both incident managers and the press who are concerned about the immediate events and damage. Prescribed burning, although of low intensity, is also widespread and now attracts close public scrutiny, mostly due to the smoke it produces. Therefore agencies face the challenge of balancing the risks to health from exposure to smoke from prescribed fires against the risks for wildfires. However, the impact on air quality in Southern Australia of the smoke from this diverse range of emission sources has not been analysed. Simplistically, one might assume, (and the press often does) health impacts are related to total emission of the smoke, whereas, in fact, they are related to the surface concentrations in the regions where people live and work; i.e. they are determined by smoke exposure. In the last decade there have been fire events covering the full range of classes: large forest fires of long duration (months), intense and destructive mega-fires of short duration (days) and a background of extensive prescribed burning. In this paper we analyse the smoke dispersion and surface impacts from three fires: the 2006/7 Alpine fires that burned approximately 1.1 Mha of forest and persisted for 60 days, the catastrophic Kilmore East fire on Black Saturday (Feb $8^{\text {th }}$ 2009), which burned 93 kha but persisted for less than a day, and a prescribed burning event in the Huon Valley of Tasmania in April 2010, which fumigated Geeveston and attracted the focus of public attention for its assumed health impacts.

\section{FIRE REGIMES}

Statistics from annual reports of the fire agencies show that in the last 30 years the annual area of Victoria burned by prescribed fire and wildfire has averaged 120 kha and 186 kha respectively (Figure 1) or $1.5 \%$ and $2.4 \%$ of the 7.8 Mha of public land (Table 1). The annual variability is wide 30 to 210 kha and 10 to 1400 kha for prescribed burns and wildfires respectively. Error! Reference source not found.With the exception of extreme fire years of 1983 and 1984, until 2003 prescribed burning accounted for approximately $70 \%$ of the burned area. Most fires of both classes are small; however a few large fires typically account for a large fraction of the total area burned, particularly for wildfires, where the largest fires accounted for up to $81 \%$, and the 5 largest fires accounted for up to $96 \%$ of the total area burned annually. The extreme fire years are a little different: the alpine fires of 2003 and 2007 each consumed approximately $18 \%$ of public forest; and the 2009 fires were slightly less extensive, consuming 10.5\% (Figure 1).

The picture, then, is one of widespread regular prescribed burns across Victoria, supplemented by wildfires and therefore, for most of the time, the smoke impact will be mostly from planned burns. On rare occasions (four events in 33 years), there are extreme wildfires. While low intensity fires disperse smoke into the lower atmosphere with the likelihood of local surface impact, high intensity fires develop convection columns that distribute smoke through the daytime convective boundary layer and into the troposphere. These plumes are 
likely to be widely dispersed. The three case studies presented in the next sections cover these three classes of fires.

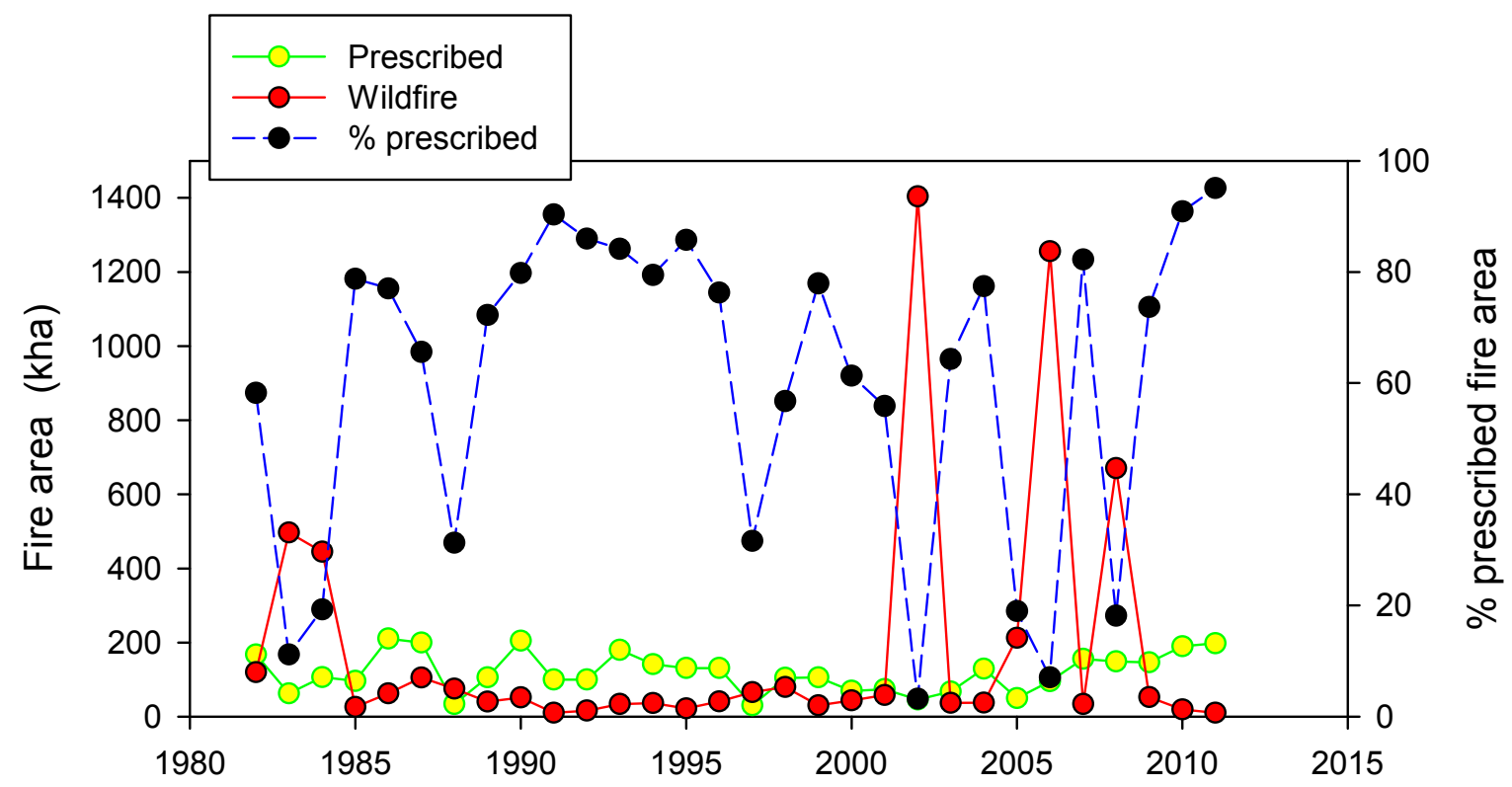

Fire season

Figure 1. Annual area of prescribed fire and wildfire, and the fraction of total annual fire area that is prescribed.

Table 1. Annual fire statistics for Victorian fire seasons 1980 to 2012 for areas under the jurisdiction of the Victorian Government Department of Environment and Primary Industry (DEPI).

\begin{tabular}{|c|c|c|c|c|c|}
\hline & \multicolumn{2}{|c|}{ Prescribed } & \multicolumn{3}{|c|}{ Wildfire } \\
\hline & All & $\begin{array}{c}\text { 1980-2012 } \\
\text { Annual } \\
\end{array}$ & All & $\begin{array}{c}\text { 1980-2012 } \\
\text { Annual } \\
\end{array}$ & $\begin{array}{l}1980-2012^{1} \\
\text { Excluding extremes }\end{array}$ \\
\hline Number & 318 & $90-1073$ & 67 & $11-223$ & $7-119$ \\
\hline Mean area per fire (ha) & 284.5 & $109-1102$ & 2195 & $75-12,700$ & $75-3625$ \\
\hline Median area pre fire (ha) & 42.0 & $15-180$ & 28.9 & $13-187$ & $13-187$ \\
\hline Largest fire & & & & & \\
\hline Mean area (ha) & & & $1,307,000$ & $756-1,307,000$ & $585-137,000$ \\
\hline$\%$ Total area & & & & $12-88$ & $12-81$ \\
\hline 5 largest fires & & & & & \\
\hline Mean area (ha) & & & 590,000 & $440-313,000$ & $422-62,000$ \\
\hline$\%$ Total area & & & & $48-98$ & $48-96$ \\
\hline$\%$ total forest area & 1.5 & $0.25-3.9$ & 2.4 & $0.1-18$ & $0.1-5.7$ \\
\hline
\end{tabular}

excludes extreme fire years 2003, 2007 and 2009.

\section{METHODS}

The cases studies addressed here are:

(1) the Alpine fires of 2006/7, which burned 1.2 Mha between 8th December 2006 and early February 2007 over a period of 60 days;

(2) the Kilmore East fire on Black Saturday, 8th February 2009. This fire was ignited at approximately 11:00 $\mathrm{h}$ and burned approx. $93 \mathrm{kha}$ of forest and urban interface over the next 12 hours.

(3) a series of high intensity regeneration burns were ignited in the Huon Valley between 16th and the 19st April 2010. 
Meyer et al., Smoke impacts from prescribed burning in Victoria; developing a risk climatology.

Fifty six coupes totalling 500 ha and $50 \mathrm{Mt}$ fuel were burned over a period of 5 days. Details of the last event are given in Meyer et al. (2011) and Reisen et al. (2013).

Smoke impacts were assessed using the following approach. The spatial and temporal pattern of PM2.5 emissions were estimated from the recorded daily or hourly fire spread and provided as input to a chemical transport model (CTM), which in turn, calculated the dispersion producing as output the estimated hourly surface concentrations across the model domain. The spatial distribution of surface PM2.5 concentrations was then combined with the spatial distribution of the residential population to estimate the impact (Eq. 1).

$$
I=R *(P * D) * \frac{P M 2.5_{f}}{10} * \frac{T}{365},
$$

where: $I=$ impact (deaths); $R$, is the risk response factor; $P$ is population; $D$ is the baseline rate of the risk (annual events per unit of population); $[\mathrm{PM} 2.5]_{\mathrm{f}}$ is the mean 24-h surface concentration of PM2.5 due to the smoke $\left(\mu \mathrm{g} \mathrm{m}^{-3}\right)$ and $T$ is the duration of the smoke event (days).

The risk factor and the baseline to which it applies could be any risk (e.g. cardiac events, asthma or other respiratory attacks), however the application of Eq. 1 in this study is to integrate, spatially and temporally, the combination of the distributions of surface PM2.5, population and susceptibility to produce a comparative risk estimate for each case study. There are sufficient data available to apply Eq. 1 to mortality, and therefore we take $I$ to be the increased mortality due to exposure to smoke and the mortality risk factor for all ages and causes (1\% increase in mortality per $10 \mu \mathrm{g} \mathrm{m}^{-3}$ increase in PM2.5) suggested by Pope and Dockery (2006), while probably conservative, is suitable for comparative purposes. The baseline to which the risk factor is applied can be estimated, spatially, from statistics provided by the Australian Bureau of Statistics (ABS); $P$ is taken from the ABS 2011 census and resolved to SA1 districts; $D$ is the normalised death rate from all causes and is sourced from ABS statistics resolved to SA2 districts. To minimize the effects of inter-annual variability in death rate we apply the median death rate for the period 2006 to 2011 . The surface concentration of PM2.5 gives the maximum likely exposure; in practice many people will be indoors, and therefore the actual exposure will be attenuated. An analysis of this is given in Meyer et al. (2010).

\subsection{Emissions.}

The smoke emissions modelling is a simplified version of the method developed by Meyer et al. (2008), with three variants: the fire locations and progressions were known from ground and line scanner surveys and therefore there was no requirement for satellite mapping from remote sensing. Some improvements were applied to the spatial fuel load estimates and we applied the emission factor for PM2.5 for extraptropical forest of $13 \mathrm{~g} \mathrm{PM} .5$ ( $\mathrm{kg}$ fuel) $^{-1}$ (Andreae and Merlet, 2001). Daily fire boundaries were available for the alpine fire (case study 1), and these were further time resolved to the hourly time step required for the dispersion modelling using the diurnal pattern of emissions developed by Meyer et al. (2008) for northern Australia. This was not required for case study 2 because its fire progression was known to better than an hour. Fire locations and area were known for case study 3 ; however the timing of ignition was not. Based on advice from Forestry Tasmania (Tony Blanks, pers. com.) it was assumed that all coupes were ignited at 11:00 h. Fuel loads for case study 1 were the approach of followed Meyer et al., (2008). Case study 2 fuel loads were based on the fuel layer currently used in the fire spread model, Phoenix Rapid-fire (Tolhurst et al., 2008), supplemented with VAST (Barrett, 2010) on unmapped private land. For case study 3, the fuel load was assumed to be $100 \mathrm{t} \mathrm{ha}^{-1}$ (Meyer et al., 2012).

\subsection{Dispersion Modelling}

To calculate dispersion we applied two models. Meteorological modelling was undertaken using CSIRO TAPM (Hurley et al., 2009), a nestable, three-dimensional Eulerian numerical weather and air quality prediction system. This model was used to generate meteorological fields which including wind velocity, temperature, water vapour mixing ratio (including clouds), radiation and turbulence. The air quality component of TAPM, which includes a simple chemical transformation mechanism, was used only for case study 3. For the other cases, dispersion modelling was undertaken using the CSIRO Chemistry Transport Model (CTM; Cope et al. 2004). The CTM is a three-dimensional Eulerian chemical transport model with the capability of modelling the emission, transport, chemical transformation, wet and dry deposition of an arbitrary number of gaseous and aerosol species. Transport is highly dependent of plume injection height. In all case studies this was prescribed based on observations of the plumes rise from space borne LIDAR (CALIPSO) for case study 1 and the Bureau of meteorology radar (case study 2). In both case studies 1 and 2 plume rise was set to the convective boundary layer (CBL) height. The was a good approximation for case study 1 where the observed daytime CBL was $1000-2000 \mathrm{~m}$ but an underestimate for case study 2 where the 
Meyer et al., Smoke impacts from prescribed burning in Victoria; developing a risk climatology.

plume rise observed by radar was approximately $6000 \mathrm{~m}$ at its maximum. Applying the CBL height in case study 2 will give will give an upper estimate of likely ground level PM2.5 concentrations which, in a scoping study such as ours, is acceptable. In case study 3 , the plumes were released into the lower layers of the model to $300 \mathrm{~m}$; this approximates the average atmospheric mixing depth during the day during the event.

The models used have been extensively tested and validated previously (e.g. Luhar et al., 2008; Meyer et al., 2012). Part of this study, the predicted concentrations from case 1 were compared with hourly observations of PM2.5 or PM10 and ozone and from all the Melbourne air quality stations and were found to be accurate. These data will be published elsewhere.
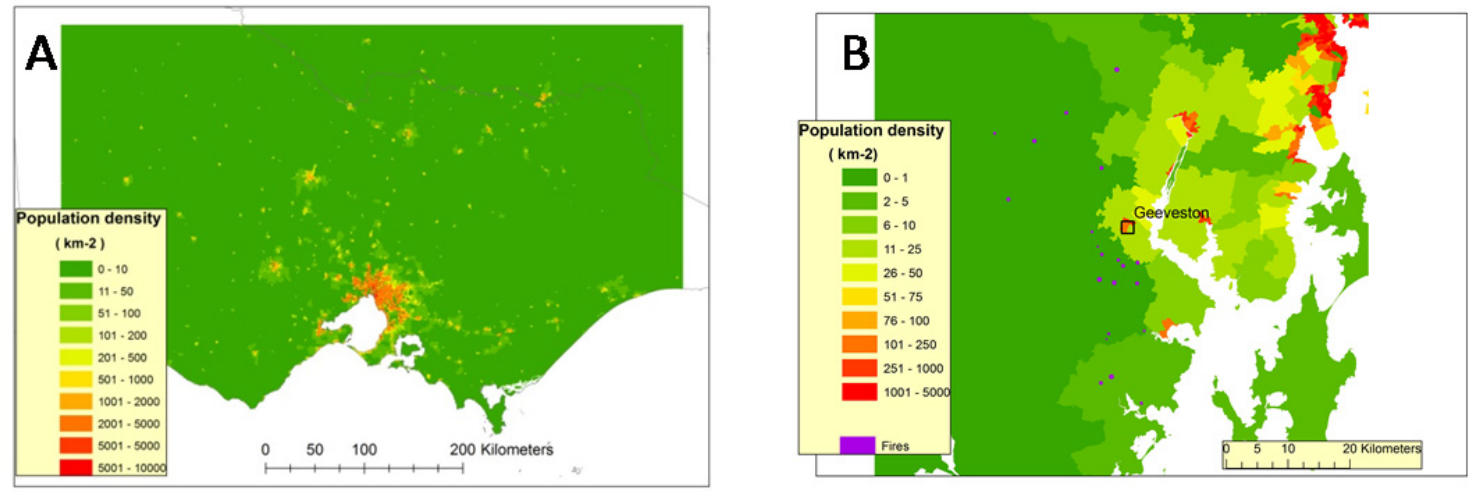

Figure 2. Population density in A: Victoria; and B: Huon Valley Tasmania.

The locations of the high intensity prescribed burns are shown as purple circles.

\section{RESULTS}

The population of rural Victoria and the Huon Valley is sparse with widely spaced regional cities and towns (Figure 2). The exception is Melbourne which houses most of the population of Victoria. The Kilmore East fire was slightly beyond the northern rural urban interface of Melbourne; the alpine fire was $200 \mathrm{~km}$ to the north east. The fires in the Huon valley were south of Geeveston, or in the upper reaches of the Huon river, $\mathrm{NE}$ of Geeveston and isolated from it by the main ridge. The closest coupes were $6 \mathrm{~km}$ from Geeveston (Figure 2B).

The average PM2.5 concentrations across the model domains for the full duration of each of the case studies are presented in Figure 3. In all cases the PM2.5 concentrations were highest near the source but extended at lower concentrations over large areas of all domains. In case study 1, all of the state was impacted to some degree, with $30 \%$ of the total state averaging more than the national standard of $25 \mu \mathrm{g} \mathrm{m}^{-3}$; the plume mostly impacted area NW of the source but with a spur extending SW over Melbourne and potentially exposing a large population to the hazard. The impact from case study 2 was similarly widespread affecting 750 kha, north of the fire; however the impacts persisted for only a day and significantly impacting only one regional city, Shepparton. The modelled plume in case study 3 was also extensive, but dispersed to the south, away from the populated areas of the Huon Valley, and there was no indication that smoke persisted or was trapped in the valley.

Table 2 presents shows results of applying Eq. 1 to estimate the health risk resulting from the impact of dispersed PM2.5 on the population. The long duration and widespread dispersion of PM2.5 in case study 1 posed a major risk to health. Assuming the validity of the risk factor applied here, this suggests that 84 additional deaths could have resulted from the event, mostly associated with the plume strikes on Melbourne (Figure 3D). These health impacts were probably greater than all other risks to persons during the 2006 alpine fire, and the number is significant even in comparison to the Black Saturday fires which caused the 173 deaths. The health impacts from case studies 2 and 3 were minor. Therefore, it is the long-lived event that poses the greatest risk. Health impacts from short-lived events depend largely on the plume dispersion dynamics on the day.

The health risks do not scale with total carbon emission. Relative to case study 3, emissions in case studies 2 and 1 are respectively 53 and 1110 fold greater compared to health risks that were 7 and 5500 fold greater. Much of the public perception of health risks from smoke is based on emission rate rather than the combination of emission and dispersion, but clearly, on its own, emission rate is a poor indicator of health impact. 
Meyer et al., Smoke impacts from prescribed burning in Victoria; developing a risk climatology.

\section{DISCUSSION AND CONCLUSIONS}

Dispersion of smoke from persistent fires is determined by the seasonal climatology, with the likelihood that even when population centres are upstream of the prevailing winds there will be occasions when dispersion carries plumes to the city airsheds. In contrast, severe wildfires of short duration develop strong convection columns that disperse smoke high into the troposphere, minimising the risk of ground strike; although local regions downwind of the event will invariably be impacted to some degree. Prescribed burns, because they are managed, can be timed to avoid plume strike on sensitive regions.

It is also clear that the magnitude of the smoke emission does not imply the magnitude of the smoke impact. This is particularly relevant to case 3 , which caused significant public comment at the time largely due to the visibility of the plume. Contrary to perception, the modelling of this event showed that smoke did not accumulate in the Huon valley, and as was confirmed by Meyer et al., (2011) and Reisen et al., (2013) posed only a relatively minor risk to the population.

However, in most years, most smoke is produced by prescribed fires. These are widely distributed across the state and therefore even if the impacts are mostly local and of short duration, because the fires are distributed, collectively they have the potential for impacting large regions. The total effect may well be similar to a large protracted wildfire (such as case study 1) the health impacts of which derive from widespread dispersion and long duration. The imperative to increase the area burned annually in Victoria by $250 \%$ to 400 kha per year and the short prescribed burning season brings prescribed burning for some jurisdictions into the scale of large wildfire events, at least with respect to smoke production and its regional impact. Managing these fires to avoid significant health impact will be an increasing challenge for managers. Systems for modelling smoke dispersion will become an increasingly important component of the fire managers' toolkit.
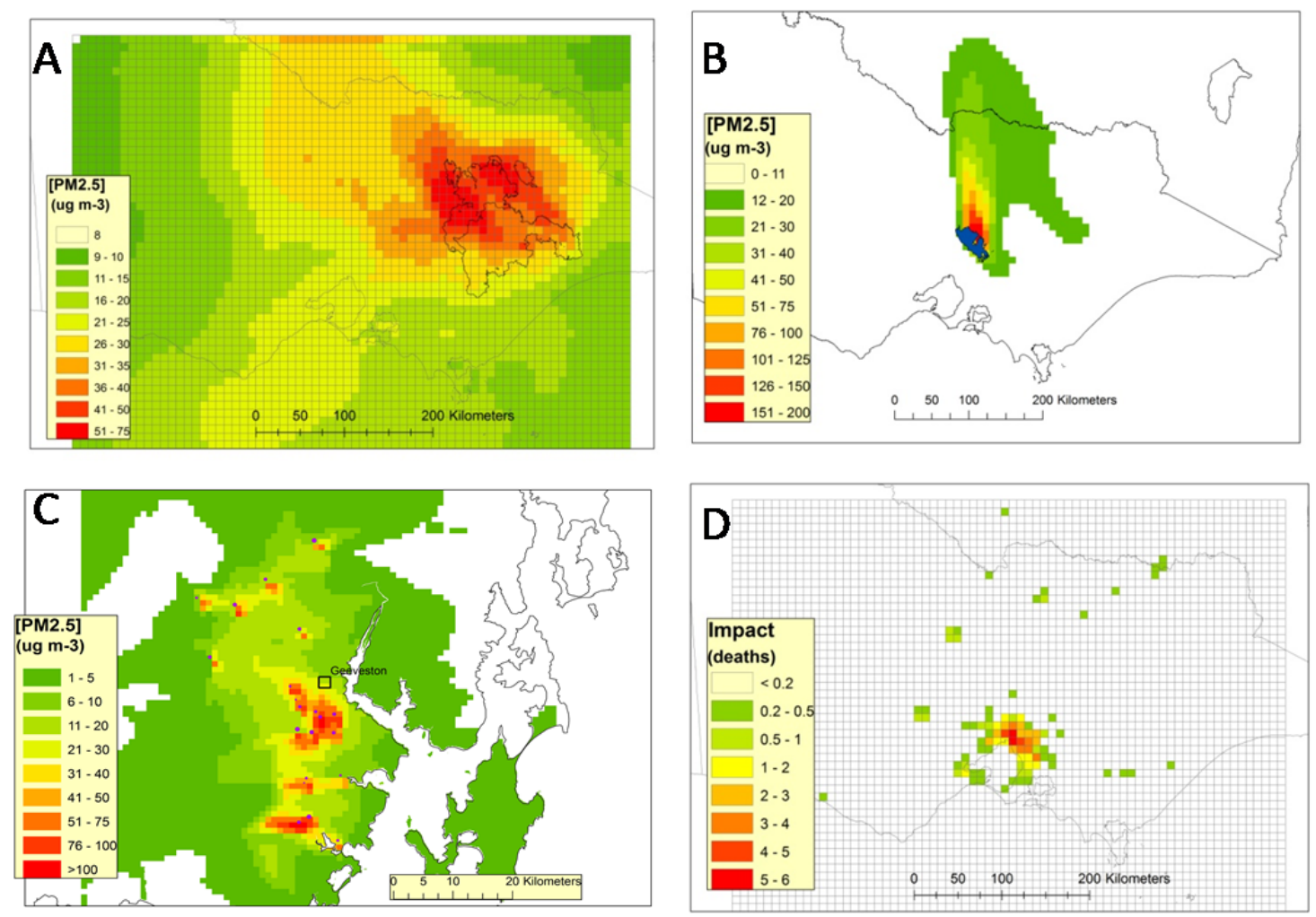

Figure 3. Mean surface concentrations of PM2.5 during the fire events at A: Alpine fires (Case 1; fire boundary is shown in outline); B: Kilmore E (Case 2; fire areas shown in purple); and C: Huon Valley (Case 3; fire area is shown in blue). D: Health Impacts (Additional deaths due to smoke) from Alpine fires (Case 1). 
Meyer et al., Smoke impacts from prescribed burning in Victoria; developing a risk climatology.

Table 2. Relative health impacts of the case studies

\begin{tabular}{|c|c|c|c|c|c|c|c|c|}
\hline & & & & \multicolumn{4}{|c|}{ Impacted zone } \\
\cline { 6 - 10 } Fire & Start date & Days & \multirow{2}{*}{$\begin{array}{c}\text { Area } \\
\left(\mathrm{km}^{2}\right)\end{array}$} & $\begin{array}{c}\text { Emission } \\
(\mathrm{kt} \mathrm{C})\end{array}$ & $\begin{array}{c}\text { Area } \\
\left(\mathrm{km}^{2}\right)\end{array}$ & $\begin{array}{c}\text { Population } \\
(1000 \mathrm{~s})\end{array}$ & $\begin{array}{c}\text { Baseline } \\
\left.\text { (deaths y }^{-1}\right)\end{array}$ & $\begin{array}{c}\text { Impact } \\
(\text { deaths })\end{array}$ \\
\hline Alpine & $8 / 12 / 2006$ & 60 & 11,400 & 28,700 & 212,600 & 5,370 & 34,611 & 84 \\
Kilmore & $8 / 02 / 2009$ & 1 & 925 & 1,340 & 50,200 & 270 & 1,745 & 0.10 \\
Huon & $16 / 04 / 2010$ & 6 & 5.5 & 25 & 1,275 & 4.36 & 30 & 0.015 \\
\hline
\end{tabular}

\section{ACKNOWLEDGEMENTS}

We wish to thank the Bushfire CRC for its support of this project and the Dept. of Environment and Primary Industry, Victoria, and Forestry Tasmania for their advice and for access to their spatial fire databases.

\section{REFERENCES}

Barrett, D. J. (2010). Timescales and Dynamics of Carbon in Australia's Savannas, in: Ecosystem Function in Savannas: Measurement and Modeling at Landscape to Global Scales, edited by: Hill, M.J. and Hanan, N. P., CRC Press, 347-366, 2010.

Cope M. E., Hess, G. D., Lee, S., Tory, K., Azzi, M., Carras, J., Lilley, W., Manins, P. C., Nelson, P., Ng, L., Puri, K., Wong, N., Walsh, S., and Young, M. (2004). The Australian Air Quality Forecasting System. Part I: Project Description and Early Outcomes. J. Appl. Meteorol., 43, 649-662.

Hurley, P. J. (2009). The Air Pollution Model (TAPM) version 4. Part 1. Technical description. Aspendale, Vic.: CSIRO Atmospheric Research. (CSIRO Atmospheric Research technical paper; 71 ). 54 p.

Johnston, F.H., Bailie, R.S., Pilotto, L.S., Hanigan, I.C. (2007). Ambient biomass smoke and cardio respiratory hospital admissions in Darwin, Australia, BMC Public Health, 7, 240. doi: 10.1186/1471-2458-7-24.

Lepeule, J., Laden, F., Dockery, D., and Schwartz. J. (2012). Chronic Exposure to Fine Particles and Mortality: An Extended Follow-up of the Harvard Six Cities Study from 1974 to 2009, Environ Health Perspect. 120, 965-970.

Luhar, A. K., R. M. Mitchell, C. P. Meyer, Y. Qin, S. Campbell, J. L. Gras and D. Parry (2008). "Biomass burning emissions over northern Australia constrained by aerosol measurements: II-Model validation, and impacts on air quality and radiative forcing." Atmospheric Environment, 42, 1647-16

Meyer, C. P., A. K. Luhar and R. M. Mitchell (2008). "Biomass burning emissions over northern Australia constrained by aerosol measurements: I-Modelling the distribution of hourly emissions." Atmospheric Environment 42, 1629-1646.

Meyer, C.P. (Mick), Reisen, F, Keywood, M. and Crumeyrolle, S. (2011). Impacts of smoke from regeneration burning on air quality in the Huon Valley, Tasmania, Final report to Forestry Tasmania, CSIRO Marine and Atmospheric Research, August 2011, 78p.

Meyer, C.P, Cope, M. Lee, S., Young, S. and Keywood, M. (2012). Development of accounting and verification methodologies for biomass burning emissions from Australian Savanna Woodlands Final report to Northern Australian Indigenous Land and Sea Alliance ,CSIRO Division of Marine and Atmospheric Research, November $2012,54 \mathrm{p}$.

Miller, K.A., Siscovick, D.S., Sheppard, L., Shepherd, K., Sullivan, J.H., Anderson, G.L. and Kaufman JD. (2007). Long-term exposure to air pollution and incidence of cardiovascular events in women. N Engl J Med. 1, 356, 447-58.

Pope, C.R., and Dockery, D.W. (2006). Health Effects of Fine Particulate Air Pollution: Lines that Connect, J. Air \& Waste Manage. Assoc. 56:709-742.

Reisen, F. and Brown S.K. (2009). Australian firefighters' exposure to air toxics during bushfire burns of autumn 2005 and 2006, Environ Int., 35, 342-352.

Teague, B., McLeod, R., and Pascoe, S. (2010). Final Report Summary, 2009 Victorian Bushfires Royal Commission, Parliament of Victoria, 52p.

Reisen, F., C. P. Meyer and M. D. Keywood (2013). Impact of biomass burning sources on seasonal aerosol air quality. Atmospheric Environment, 67: 437-447.

Tolhurst, K.G., Shields, B.J. and Chong, D.M. (2008). PHOENIX: development and application of a bushfire risk management tool. Australian Journal of Emergency Management, 23(4), 47-54. 